\title{
Complete Balanced Atrioventricular Septal Defect - Results of Bi-ventricular Surgical Correction
}

\author{
Michał Sobieraj', Michał Szemień', Marcin Bednarek', Michał Wojtalik², \\ Wojciech Mrówczyński \\ ${ }^{1}$ Pediatric Cardiac Surgery Students' Interest Group, Poznan University of Medical Sciences, Poland \\ ${ }^{2}$ Department of Pediatric Cardiac Surgery, Poznan University of Medical Sciences, Poland
}

\begin{abstract}
Aim. The aim of this study was to analyze the results of surgical treatment of balanced AVSD during 10-year period in a single center. The adequacy of atrioventricular valves reconstruction was scrutinized as well as risk factors for mortality, redo surgery, pulmonary hypertension incidence were assessed.

Materials and method. One hundred twenty one patients underwent surgical correction of AVSD between 2004 and 2013. All patients were operated by double patch technique with the apposition zone closure. Patients' median age was: 109 (86-151) days, body weight: 4.5 (4-5.5) kg. Down syndrome was present in 100 (82.6\%) patients.

Results. Early mortality equaled $17.3 \%$ (21 patients) and late mortality was $1.7 \%$ (2 patients). Pulmonary hypertension (42.9\%) and heart failure $(33.3 \%)$ were the main causes. Cardiopulmonary bypass time $(p<0.0001)$, aortic cross-clamping time $(p=0.003)$, inotropic index value $(p<0.0001)$, maximal mean pulmonary artery pressure $(p=0.008)$ were significantly higher in the group of patients who died. Ten patients $(8.3 \%)$ required early reoperation and nine (9\%) required late reoperation. Early postoperative mitral valve regurgitation of III-rd or higher degree was risk factor for early and late reoperations $(p=0.0002)$. The probability of freedom from all reoperations at 6 months, 1 and 5 years was respectively: $0.83 ; 0.80$ and 0.71 .

Conclusions. Pulmonary hypertension and low cardiac output syndrome have significant influence on results of AVSD treatment. The predisposing risk factors are prolonged time of surgical procedure and presence of pneumonia. Mitral valve reconstruction quality has an influence for early and late results.
\end{abstract}

Keywords: AVSD, mitral valve regurgitation, redo surgery.

\section{Introduction}

Atrioventricular septal defect (AVSD) is a complex cardiac malformation comprising entire spectrum of different defects: isolated cleft of anterior mitral valve leaflet, ostium primum atrial septal defect, ostium primum atrial septal defect with ventricular septal defect (VSD), transitional AVSD type, and finally a complete AVSD. The later can occur in more severe unbalanced form.

Anatomy and pathophysiology of the malformation causes $60-65 \%$ mortality rate in first year of life and over $90 \%$ in first two years. Thus, the only definitive treatment is a surgical correction with reconstruction of atrioventricular valves - the most crucial part of surgical approach. Even though progress in cardiac surgery techniques improved outcomes of patients with AVSD including quality of life, still $15-20 \%$ patients require reoperation [1-3]. The most common indication for reoperation after initial repair is a regurgitation of atrioventricular valves, particularly mitral insufficiency which is the cause of reoperation in $70-90 \%[2,4,5]$.

Surgical correction of AVSD can be complicated by other different problems including: post-operative pulmonary hypertension (PH), low cardiac output syndrome (LCOS) and III atrioventricular heart block. 


\section{Aim}

The aim of the study was to assess the results of surgical bi-ventricular correction of complete AVSD during 10 -year period in a single unit. The risk factors of atrioventricular valves regurgitation, intraoperative mortality, pulmonary hypertension and other complications were studied.

\section{Materials and method}

Patients

One hundred twenty one patients underwent surgical correction of AVSD in the Department of Pediatric Cardiac Surgery in the University of Medical Sciences, Poznań, between 2004-2013. Patients with isolated cleft of anterior mitral valve leaflet, partial, transitional and unbalanced forms of AVSD were excluded. Medical records (surgical reports, case histories, local medical data base and local data from National Cardiac Surgery Register) were reviewed.

Ten patients underwent pulmonary artery banding before primary correction. Seven patients (5.79\%) had coexisting malformations like pulmonary valve stenosis ( $n=3 ; 2.5 \%)$, tetralogy of Fallot $(n=1 ; 0.8 \%)$, and coarctation of the aorta ( $\mathrm{n}=1 ; 0.8 \%)$. Demographic data are shown in Table 1.

This observational study has been approved by the local Ethics Committee (resolution: 32/13 from 03.01.2013) and an individual patients' consent was waived.

Table 1. AVSD patients characteristics

\begin{tabular}{lc}
\hline \multicolumn{2}{c}{ Demographic variables } \\
\hline $\mathrm{N}$ & 121 \\
\hline Gender (female/male) & $58(47.9 \%) / 63(52.1 \%)$ \\
\hline Down's syndrome & $100(82.6 \%)$ \\
\hline Age (days) & $109(86-151)$ \\
\hline Body weight (kg) & $4.5(4-5.5)$ \\
\hline Body surface area (m²) & $0.26(0.24-0.30)$ \\
\hline \multicolumn{3}{c}{ Intraoperative variables } \\
\hline CBP (min) & $119(103-138)$ \\
\hline Ao-x-clamp (min) & $74(63-88)$ \\
\hline & $10(6-20)$ \\
\hline ICU time (days) & $96(32-266)$ \\
\hline Mechanical ventilation (hours) & $15(6.70-24.85)$ \\
\hline INO SCORE (mcg/kg/min) & $49.2 \pm 18.2$ \\
\hline Max. mPAP (mmHg) &
\end{tabular}

CBP - cardiopulmonary bypass time; Ao-x-clamp - aortic cross-clamp time; INO SCORE - inotropic index; ICU time - intensive care unit stay time; Max. MPAP maximal mean pulmonary artery pressure
Surgical technique

All patients were operated through the median sternotomy by applying two-patch technique $[6,7]$, with the use of aorto-bicaval cannulation for cardiopulmonary bypass in moderate hypothermia. Cardiopulmonary bypass time (CBP) and aortic cross clamping time (Ao-x-clamp) were recorded. Ventricular septal defect was closed with Gore-Tex patch attached to interventricular septum by a continuous suture. Then the division and reconstruction of atrioventricular valves was performed. The left-sided apposition zone of bridging leaflets was sutured with interrupted 6-0 polypropylene monofilament sutures. Autologous pericardium was applied for atrial septal defect closure. Regurgitation of reconstructed atrioventricular valves was tested saline injection into the ventricle and by the use of intraoperative transesophageal echocardiography.

\section{Post-operative care}

All patients received standard intensive care unit treatment. When necessary pulmonary artery pressure was recorded by a catheter inserted through the infundibulum of the right ventricle. Pulmonary hypertension was treated by hyperventilation, nitric oxide inhalation, and phosphodiesterase $\mathrm{V}$ inhibitors administration via nasogastric tube (sildenafil). Pharmacological circulatory support was obtained by catecholamines and vasodilatators: adrenaline, isoprenaline, dopamine, dobutamine and milrinone. The degree of catecholamine support was expressed by inotropic index $[8,9]$, defined as: INO-SCORE $(\mathrm{mcg} / \mathrm{kg} / \mathrm{min})=$ $D P A+D B X+100 x I S O+100 \times A D R$, (where: $D P A=$ dopamine, $\mathrm{DBX}=$ dobutamine, $\mathrm{ISO}=$ isoprenaline, $\mathrm{ADR}=$ adrenaline). One patient required mechanical circulatory support - ECMO due to heart failure refractory to conventional treatment.

\section{Echocardiographic study}

Transthoracic echocardiography was performed in all patients preoperatively, pos-operatively and during the follow-up. Left ventricular ejection fraction (LVEF), left ventricular shortening fraction (SF), common atrioventricular valve regurgitation (CAVVI), mitral (MI) and tricuspid ( $\mathrm{TI})$ valve regurgitations were analyzed.

\section{Follow-up}

Transthoracic echocardiography and medical examination were performed in all patients during the follow-up. Median observation time was 714 days (4201002). Total follow-up was 143.5 patient-years. 


\section{Statistical analysis}

Normality of data distribution was tested by Kolmogorov-Smirnov test. Continuous variables were presented as mean and standard deviation or median and range according to the distribution normality. T-student and Mann-Whitney tests were used for intergroup independent comparisons. Fisher's exact test was employed for categorical variables comparisons. Kaplan-Meier method was applied to assess the probability of freedom from all reoperations and reoperations for significant mitral valve regurgitation, 95\% confidence interval was calculated. $P$-value less than 0.05 was considered statistically significant.

\section{Results}

\section{Mortality}

Thirty-day mortality equaled $17.3 \%$ (21 patients). Nine patients died from pulmonary hypertension (42.9\%), 7 from heart failure (33.3\%), 2 from coexisting pulmonary hypertension and heart failure (9.5\%). Multiple organ dysfunction syndrome was the cause of 3 deaths (14.3\%). Late mortality (> 30 days) was $1.7 \%$ ( 2 deaths). Both patients died from coexisting pulmonary hypertension and heart failure.

Prolonged cardiopulmonary bypass time, prolonged aortic cross-clamping time, higher inotropic index and higher maximal mean pulmonary artery pressure were influencing negatively the survival with statistical significance (Table 2). Demographic data had no statis- tically significant impact on the survival. There were no statistically significant differences in: pre-operative left ventricle ejection fraction, left ventricle fractional shortening, mechanical ventilation time and presence of common atrioventricular valve regurgitation (III-rd degree or higher) in patients who died and patients who survived. There were no early and late deaths in 10 patients who underwent pulmonary artery banding before total correction in comparison to children without banding (early mortality $0 \%$ vs. $18.9 \%$ ) but this difference was not significant ( $p=0.207)$.

\section{Reoperations}

Ten patients required early reoperation ( $\leqslant 30$ days). Nine $(9 \%)$ patients out of 100 who survived early postoperative time required late reoperation (>30 days). Four patients required second redo surgery. One patient underwent third reoperation. Causes of reoperations and re-interventions are listed in Table 3. The usual redo strategy for mitral valve regurgitation was repeated mitral valve reconstruction.

The median time of early reoperation equaled 14 days (7-24). The median time of late redo surgery was 205 days (52-950). The probability of freedom from all reoperations at 6 months, 1 and 5 years was respectively: $0.83(0.75-0.92 ; 95 \% \mathrm{Cl}) ; 0.80$ (0.70-0.90; $95 \% \mathrm{Cl}$ ) and $0.71(0.56-0.90 ; 95 \% \mathrm{Cl})$ (Figure 1). Figure 2 shows freedom from the first reoperation due to the significant mitral valve regurgitation with the probability of $0.87(0.80-0.96 ; 95 \% \mathrm{Cl}) ; 0.85(0.77-0.95$;
Table 2. Mortality risk factors in patients undergoing AVSD correction

\begin{tabular}{|c|c|c|c|}
\hline Variables & Survival & Death & $p$-value \\
\hline \multicolumn{4}{|c|}{ Intraoperative variables } \\
\hline $\mathrm{CBP}$ (min) & $113(101-130)$ & $144(129-179)$ & $<0.0001$ \\
\hline Ao-x-clamp (min) & $71(62-85)$ & $91(76-103)$ & 0.0003 \\
\hline \multicolumn{4}{|c|}{ Postoperative variables } \\
\hline INO SCORE (mcg $/ \mathrm{kg} / \mathrm{min})$ & $12.9(6.0-19.1)$ & $58.5(19.3-87.5)$ & $<0.0001$ \\
\hline Max. mPAP (mmHg) & $44.8 \pm 17.4$ & $61.0 \pm 16.4$ & 0.008 \\
\hline Mechanical ventilation (hours) & $84(32-244)$ & $174(19-573)$ & 0.203 \\
\hline \multicolumn{4}{|c|}{ Demographic variables } \\
\hline Age (days) & $108(87-153)$ & $113(69-172)$ & 0.424 \\
\hline Body weight (kg) & $4.55(4-5.9)$ & $4.15(3.8-5)$ & 0.207 \\
\hline Body surface area $\left(\mathrm{m}^{2}\right)$ & $0.27(0.24-0.31)$ & $0.26(0.24-0.28)$ & 0.132 \\
\hline Down's syndrome & $84.7 \%$ & $69.6 \%$ & 0.129 \\
\hline \multicolumn{4}{|c|}{ Preoperative echocardiographic data } \\
\hline CAVVI $\geqslant I I I-r d$ degree & $32.3 \%$ & $45.4 \%$ & 0.320 \\
\hline $\operatorname{LVEF}(\%)$ & $78(71-84)$ & $78(73-81)$ & 0.812 \\
\hline SF $(\%)$ & $43(38-50)$ & $43(38-46.8)$ & 0.951 \\
\hline
\end{tabular}

Table 3. Reoperations in patients undergoing AVSD correction

\begin{tabular}{lc}
\hline \multicolumn{2}{c}{ Early reoperations } \\
\hline $\mathrm{MI}$ & 4 \\
\hline $\mathrm{MI}+\mathrm{TI}$ & 1 \\
\hline VSD & 1 \\
\hline Pacemaker implantation & 4 \\
\hline \multicolumn{2}{|c}{ Late reoperations and interventions } \\
\hline $\mathrm{MI}$ & 6 \\
\hline MI+TI & 2 \\
\hline Wound revision & 1 \\
\hline Pleural effusion drainage & 1 \\
\hline Pericardial effusion drainage & 1 \\
\hline Pacemaker implantation & 3 \\
\hline
\end{tabular}

MI - mitral valve regurgitation; $\mathrm{TI}$ - tricuspid valve regurgitation; VSD - ventricular septal defect 
$95 \% \mathrm{Cl})$ and $0.77(0.61-0.97 ; 95 \% \mathrm{Cl})$ at 6 months, 1 and 5 years respectively.

Patients with early ( $\leqslant 30$ days) III-rd or higher degree mitral valve regurgitation required significantly more reoperations than other children (22\% vs. $0 \%$ ) $(p=0.0002)$. Patients' age, body weight, body surface, cardiopulmonary bypass time, aortic cross-clamping time, inotropic index, maximal mean pulmonary artery

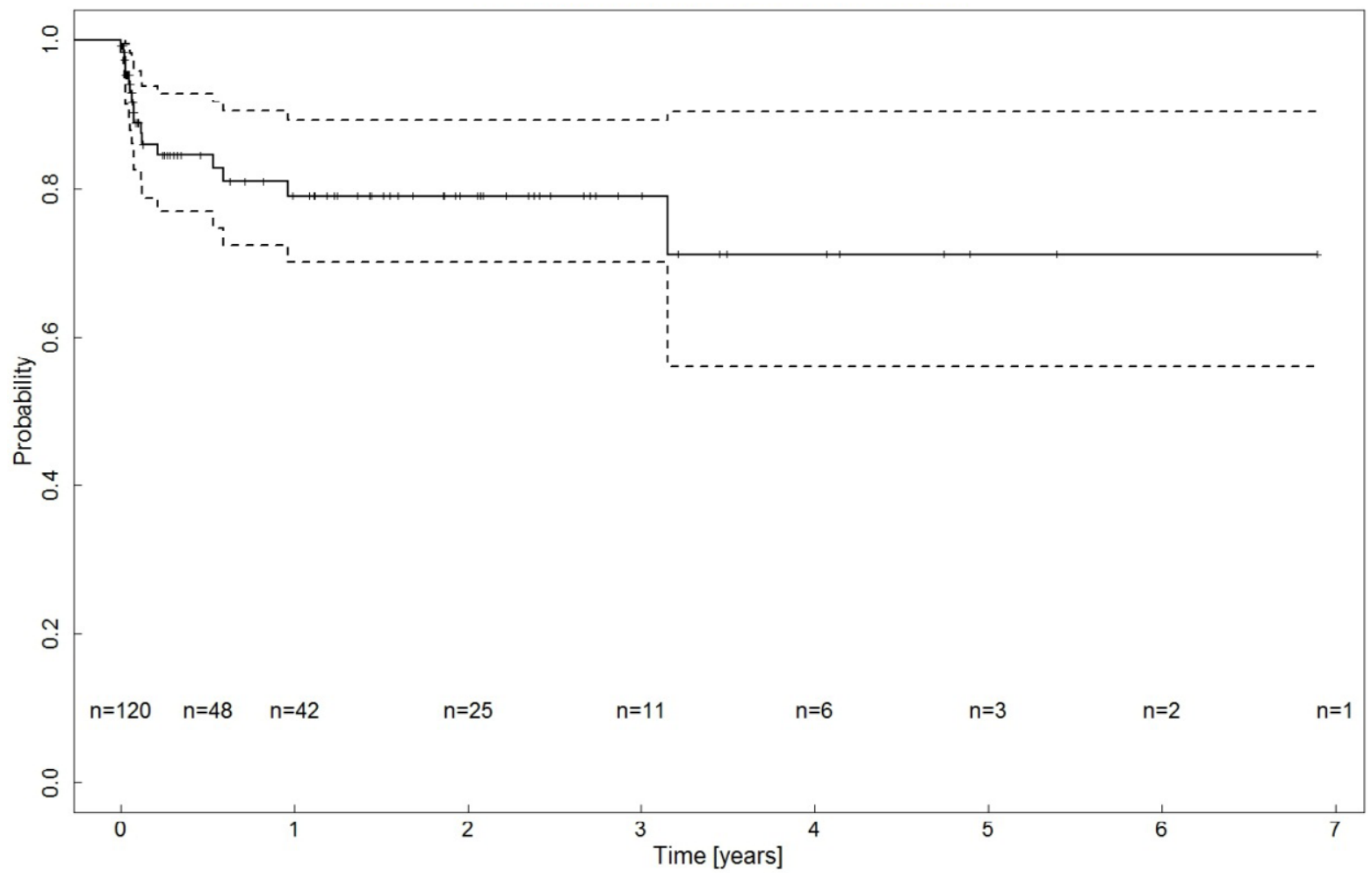

Figure 1. Freedom from the first reintervention

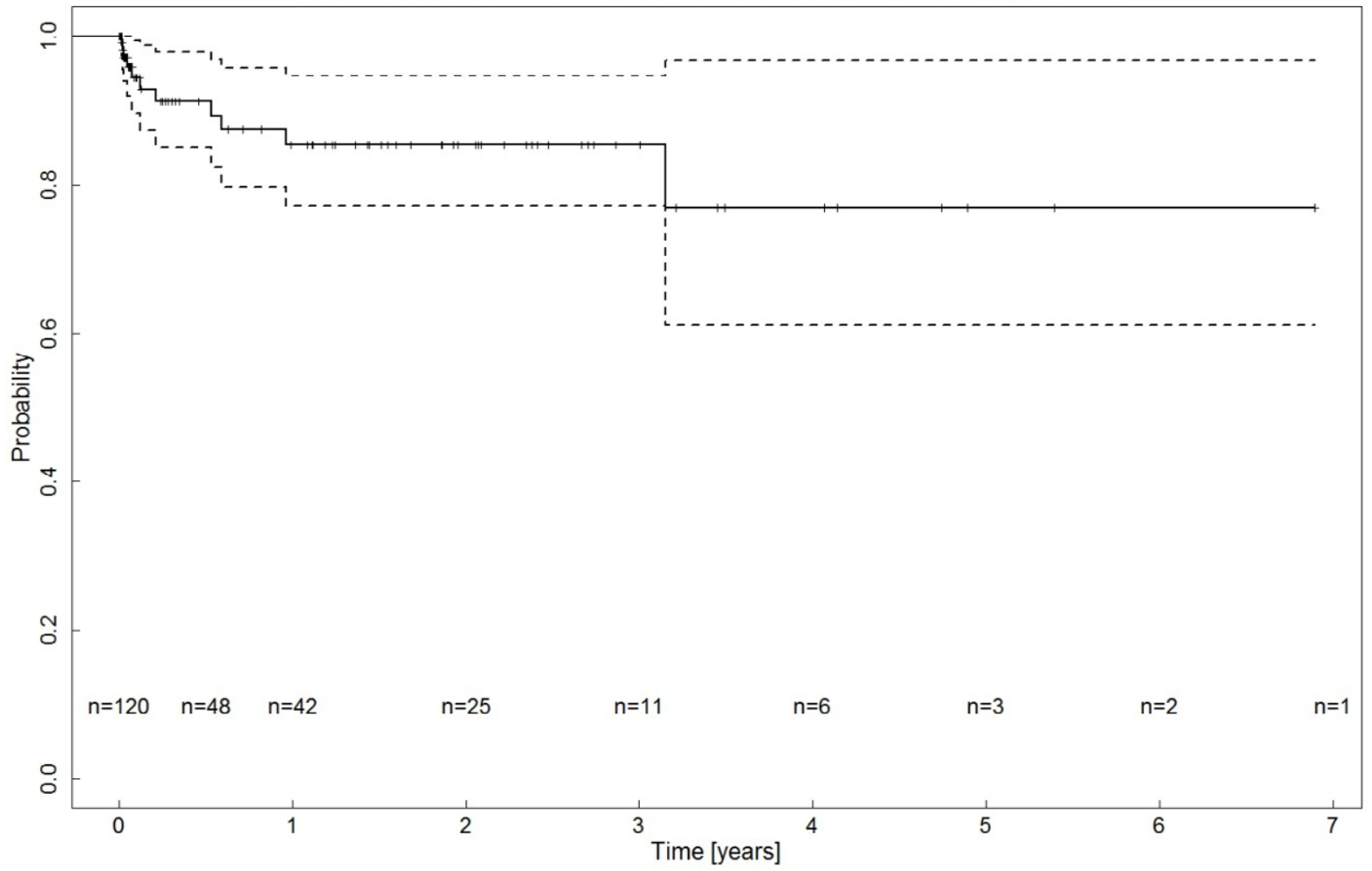

Figure 2. Freedom from the first reintervention due to mitral regurgitation 
pressure, left ventricle ejection fraction, left ventricle fractional shortening were not significantly different in the groups of children requiring redo mitral valve surgery and in the group of patients without reoperation. Presence of preoperative III-rd or higher degree common atrioventricular valve regurgitation was not significantly more frequent in patients undergoing redo surgery (Table 4).

Patients who underwent pulmonary banding as a first stage of treatment did not require early neither late reoperations in comparison to the rest of the cohort ( $0 \%$ vs. $17.12 \%)$. However, this comparison was not statistically significant $(p=0.360)$.

\section{Atrioventricular valve function}

Ninety five $(78.5 \%)$ patients had pre-operative common atrioventricular valve regurgitation, forty patients (34.8\%) had III-rd or higher degree incompetence. In the first post-operative echocardiographic study 45 patients (44.5\%) had III-rd or higher degree mitral valve regurgitation, whereas IV-th degree mitral valve regurgitation was present in 12 patients $(12 \%)-5$ of them required early reoperation. During the follow-up 8 patients who had significant mitral valve regurgitation required reoperation. In last control echocardiographic study 5 patients had III-rd degree mitral valve regurgitation but did not require reoperation at the end of observation. The IVth degree mitral valve regurgitation was not noted at the follow-up conclusion.

\section{Post-operative complications}

Fifty two patients (43\%) had pulmonary hypertension in the immediate post-operative period. Thirty three patients (27.3\%) required nitric oxide inhalation or phosphodiesterase inhibitor $\mathrm{V}$ treatment concomitant to hyperventilation. Pulmonary artery banding resulted in significantly less frequent incidence of pulmonary hypertension during the total AVSD correction (1\% vs. $45.9 \% ; p=0.042$ ), only one patient who had pulmonary hypertension in this group required nitric oxide treatment.

Twenty one patients (17.4\%) had pulmonary hypertensive crisis (PHC). Mortality rate, cardiopulmonary bypass time, mechanical ventilation time, intensive care unit stay time, inotropic index, maximum mean pulmonary artery pressure were significantly higher and incidence of pneumonia more frequent in patients with PHC than patients without it (Table 5). In contrary, the differences in demographic variables between these two groups were not statistically relevant.

Low cardiac output syndrome that required pharmacological support was present in 33 patients (27.27\%). Cardiopulmonary bypass time, aortic cross-clamping time, mechanical ventilation time and inotropic index were significantly higher in patients with LCOS than patients without it (Table 6).

Among other post-operative complications pneumonia $(48 \%)$, metabolic acidosis $(15.7 \%)$, respiratory distress syndrome (5\%) and sepsis (1.6\%) were recognized.

Table 4. Reoperation risk factors in patients undergoing AVSD correction

\begin{tabular}{|c|c|c|c|}
\hline Variables & Reoperation & No reoperation & $p$-value \\
\hline \multicolumn{4}{|c|}{ Demographic variables } \\
\hline Age (days) & $105(69-117)$ & $112(88-174)$ & 0.133 \\
\hline Body weight (kg) & $4.35(3.9-5)$ & $4.5(4-5.9)$ & 0.293 \\
\hline Body surface area $\left(\mathrm{m}^{2}\right)$ & $0.26(0.23-0.28)$ & $0.27(0.24-0.31)$ & 0.186 \\
\hline \multicolumn{4}{|c|}{ Intraoperative variables } \\
\hline $\mathrm{CBP}(\min )$ & 139 (113-157) & $118(103-136)$ & 0.223 \\
\hline Ao-x-clamp (min) & $88(67-96)$ & $74(63-88)$ & 0.223 \\
\hline \multicolumn{4}{|l|}{ Postoperative variables } \\
\hline INO SCORE (mcg/kg/min) & $22(6-32.3)$ & $14.3(6.53-23)$ & 0.173 \\
\hline Max. mPAP (mmHg) & $52.31 \pm 14.9$ & $43.62 \pm 18.74$ & 0.295 \\
\hline \multicolumn{4}{|c|}{ Preoperative echocardiographic data } \\
\hline CAVVI $\geqslant I I I-$-rd degree & $45.4 \%$ & $34 \%$ & 0.513 \\
\hline LVEF (\%) & $76(67-85)$ & $78(72-83)$ & 0.866 \\
\hline SF (\%) & $45(35-51)$ & $43(38-48)$ & 0.702 \\
\hline
\end{tabular}


Table 5. Pulmonary hypertensive crisis risk factors in patients undergoing AVSD correction

\begin{tabular}{lccc}
\hline \multicolumn{1}{c}{ Variables } & PHC (100) & No PHC (21) & $p$-value \\
\hline & Intraoperative variables & & \\
\hline CBP $($ min) & $115(102-133)$ & $130(121-160)$ & 0.015 \\
\hline Postoperative variables & & & \\
\hline Mortality & $12 \%$ & $50 \%$ & 0.0001 \\
\hline Mechanical ventilation (hours) & $72(27-168)$ & $384(221-585)$ & $<0.0001$ \\
\hline ICU time (days) & $9(6-16)$ & $24(11-28)$ & 0.002 \\
\hline INO SCORE (mcg/kg/min) & $14.0(6-20.7)$ & $32.3(15-98)$ & 0.003 \\
\hline Max. mPAP (mmHg) & $40.6 \pm 9.6$ & $65.9 \pm 15.8$ & $<0.0001$ \\
\hline Pneumonia & $41 \%$ & $81 \%$ & 0.0013 \\
\hline & Demographic variables & & \\
\hline Age (days) & $110(85-147)$ & $106(84-174)$ & 0.719 \\
\hline Body weight (kg) & $4.5(4-5.9)$ & $4.6(3.9-5.5)$ & 0.795 \\
\hline Body surface area (m²) & $0.27(0.24-0.31)$ & $0.26(0.24-0.29)$ & 0.548 \\
\hline Gender (female/male) & $50 \% / 50 \%$ & $38 \% / 62 \%$ & 0.348 \\
\hline Down's syndrome & $83 \%$ & $81 \%$ & 0.760 \\
\hline
\end{tabular}

CBP - cardiopulmonary bypass time; INO SCORE - inotropic index; ICU time - intensive care unit stay; Max. mPAP - maximal mean pulmonary artery pressure

Table 6. Low cardiac output syndrome in patients undergoing AVSD correction.

\begin{tabular}{lccc}
\hline \multicolumn{1}{c}{ Variables } & LCOS & No LCOS & $p$-value \\
\hline CBP $(\mathrm{min})$ & $113(101-130)$ & $130(117-164)$ & 0.0002 \\
\hline Ao-x-clamp (min) & $71(62-86)$ & $81(68-93)$ & 0.035 \\
\hline Mechanical ventilation (hours) & $77.5(29-217)$ & $168(72-439)$ & 0.030 \\
\hline INO SCORE $(\mathrm{mcg} / \mathrm{kg} / \mathrm{min})$ & $12.9(6-18.7)$ & $30.2(18.8-52.3)$ & 0.0001 \\
\hline
\end{tabular}

LCOS - low cardiac output syndrome; CBP - cardiopulmonary bypass time; Ao-x-clamp - aortic cross-clamp time; INO SCORE - inotropic index

\section{Discussion}

This study analyzes the outcomes of complete AVSD correction in 121 patients in a single unit. All patients were operated with the double patch technique, which is commonly applied in many units [3, 5, 10-12]. The advantages of this method are: simpler partitioning and anchorage of bridging leaflets without a need for leaflet incision as well as potentially better protection of cardiac conduction system compared to single-patch and no patch technique. However, shorter cardiopulmonary bypass time and aortic cross-clamping time during single-patch and no-patch technique in comparison to double-patch approach can be an advantage of the formers [13]. The use of single patch/no-patch method is limited when additional intra-cardiac malformations like tetralogy of Fallot or double outlet right ventricle are present [13]. Moreover, the use if these techniques is connected with a frequent incidence of residual VSD and certain difficulties in attaching leaflets to Gore-Tech patch, which may result in dehiscence of sutured tissues, particularly in their mitral part [5, $14,15]$

Thirty-day mortality rate was $17.3 \%$. Although this results are comparable to the rates from other reports
$[2,10,16]$, it is possible to achieve mortality rates of $0-1.4 \%$ as reported by Bakhtiary [12] or Xie 0 [17]. In this study the main cause of early death was pulmonary hypertension (42.9\%). This observation is in contrast to other reports where presence of pulmonary hypertension was not such a pronounced risk factor of early death. For example, Prifti [18] reports of only $12.5 \%$ deaths caused by pulmonary hypertension, whereas the study by Gunter [5] shows no early deaths related to this complication. Risk factors analysis shows that presence of pneumonia have significant influence on pulmonary hypertension and the PHC development [19]. Other risk factors predisposing to PHC included prolonged cardiopulmonary bypass time and high inotropic index value.

The most frequent cause of early death in patients undergoing surgical correction of AVSD is a heart failure. It contributes to more than $50 \%$ of early mortality $[2,3,5,16,18]$. In our study the heart failure was the cause of 33\% deaths. Prolonged aortic cross-clamping time and prolonged cardiopulmonary bypass time were risk factors for low cardiac output syndrome. Consistent risk factors for in-hospital mortality were not defined so far. Prolonged cardiopulmonary bypass time, pro- 
longed aortic cross-clamp time, pulmonary pressure value and inotropic index value were the risk factors for in-hospital mortality. This observation is corresponding to other reports $[11,18,20]$. However, some studies are opposite to it $[2,16]$.

The demographic variables were not risk factors for mortality in this study. Although this observation is similar to other studies $[2,3,16,18,21]$, there are some contrary reports $[3,5]$. There were no early or late deaths in patient group who underwent pulmonary artery banding. No statistically significant differences in mortality were recorded between group of patients with $\mathrm{PAB}$ and patients without it. It can be explained by small group of patients who underwent pulmonary artery banding before primary correction (10 patients with PAB vs 111 without it). Similar results is reported by Gunter's [5] study.

Ten patients from our cohort (8.3\%) required early reoperations and 9 patients $(9 \%)$ required late reoperations. This reoperations rate is similar to the results reported by others $[3,5,16-18]$. The probability of freedom from re-interventions at 6 months, 1 and 5 years were $0.83 ; 0.80$ and 0.71 respectively and it is similar to other studies $[2,16,20]$. Mitral valve redo surgery was necessary in 13 patients $(54.2 \%$ of 24 reoperations including second and third reoperation). Early mitral valve regurgitation had influence on early or late reoperations frequency which is comparable to other reports $[3,10,18]$. The demographic and preoperative echocardiography variables were not a risk factors for development of mitral valve regurgitation. However, some studies define patients age, body weight and the absence of Down's syndrome as risk factors for increased reoperation rate $[2,10,16-18]$. Hoohenkerk [3] and Prifti [18] reported pre-operative atrioventricular valve regurgitation as significant risk factors for the reoperation. Some authors indicate that the closure of the apposition zone can decrease the mitral valve reoperation rate $[3,18,22]$. However, this aspect was not scrutinized as the apposition zone was always sutured during each AVSD correction in this study.

\section{Study limitations:}

This study has the following limitations. It is a retrospective observational study comprising 10-year period. Cardiopulmonary bypass and cardio-protection techniques (introduction of blood cardioplegia) have evolved during that time. It could have affected the statistical analyses. The next limitation arises from the fact that the procedures were performed by different surgeons which certainly could have had influenced the results. However, taking into account all consecutive interventions allows a global assessment of AVSD treatment results in a single unit.

\section{Conclusions}

The early results of AVSD treatment are influenced by complications occurring in the early postoperative period including pulmonary hypertension and low cardiac output syndrome. The predisposing risk factors are prolonged cardiopulmonary bypass time, prolonged aortic cross-clamping time and presence of pneumonia.

Impaired atrioventricular valvular function still remains a significant problem. Mitral valve reconstruction quality has an influence for early and late results. Mitral valve regurgitation in the early post-operative period affects early and late reoperation rate.

\section{Acknowledgements}

\section{Conflict of interest statement}

The authors declare that there is no conflict of interest in the authorship or publication of contribution.

\section{Funding sources}

There are no sources of funding to declare.

\section{References}

1. Calabro R, Limongelli G. Complete atrioventricular canal. Orphanet J Rare Dis. 2006;1:8.

2. Al-Hay AA, MacNeill SJ, Yacoub M, Shore DF, Shinebourne EA. Complete atrioventricular septal defect, Down syndrome, and surgical outcome: risk factors. Ann Thorac Surg. 2003 Feb;75(2):412-21.

3. Hoohenkerk GJ, Bruggemans EF, Rijlaarsdam M, Schoof $\mathrm{PH}$, Koolbergen DR, Hazekamp MG. More than 30 years' experience with surgical correction of atrioventricular septal defects. Ann Thorac Surg. 2010 Nov;90(5):1554-61.

4. Stulak JM, Burkhart HM, Dearani JA, Schaff HV, Cetta F, Barnes RD, et al. Reoperations after initial repair of complete atrioventricular septal defect. Ann Thorac Surg. 2009 Jun;87(6):1872-7.

5. Gunther T, Mazzitelli D, Haehnel CJ, Holper K, Sebening $\mathrm{F}$, Meisner H. Long-term results after repair of complete atrioventricular septal defects: analysis of risk factors. Ann Thorac Surg. 1998 Mar;65(3):754-9.

6. Backer CL, Mavroudis C, Alboliras ET, Zales VR. Repair of complete atrioventricular canal defects: results with the two-patch technique. Ann Thorac Surg. 1995 Sep;60(3):530-7.

7. Mills NL, Ochsner JL, King TD. Correction of Type C complete atrioventricular canal. Surgical considerations. J Thorac Cardiovasc Surg. 1976 Jan;71(1):20-8.

8. Gaies MG, Gurney JG, Yen AH, Napoli ML, Gajarski RJ, Ohye RG, et al. Vasoactive-inotropic score as a predictor of morbidity and mortality in infants after car- 
diopulmonary bypass. Pediatr Crit Care Med. 2010 Mar;11(2):234-8.

9. Gaies MG, Jeffries HE, Niebler RA, Pasquali SK, Donohue JE, Yu S, et al. Vasoactive-Inotropic Score Is Associated With Outcome After Infant Cardiac Surgery: An Analysis From the Pediatric Cardiac Critical Care Consortium and Virtual PICU System Registries. Pediatr Crit Care Med. 2014 Apr 25.

10. Michielon G, Stellin G, Rizzoli G, Milanesi O, Rubino M, Moreolo GS, et al. Left atrioventricular valve incompetence after repair of common atrioventricular canal defects. Ann Thorac Surg. 1995 Dec;60(6 Suppl):604-9.

11. Alexi-Meskishvili V, Ishino K, Dahnert I, Uhlemann F, Weng $\mathrm{Y}$, Lange PE, et al. Correction of complete atrioventricular septal defects with the double-patch technique and cleft closure. Ann Thorac Surg. 1996 Aug;62(2):519-24.

12. Bakhtiary F, Takacs J, Cho MY, Razek V, Dahnert I, Doenst $T$, et al. Long-term results after repair of complete atrioventricular septal defect with two-patch technique. Ann Thorac Surg. 2010 Apr;89(4):1239-43.

13. Myers PO, Cikirikcioglu M, Aggoun Y, Murith N, Kalangos A. No-patch technique for complete atrioventricular canal repair. Ann Thorac Surg. 2010 Jul;90(1):317-9.

14. Capouya ER, Laks H, Drinkwater DC, Jr., Pearl JM, Milgalter E. Management of the left atrioventricular valve in the repair of complete atrioventricular septal defects. J Thorac Cardiovasc Surg. 1992 Jul;104(1):196-201.

15. Hanley FL, Fenton KN, Jonas RA, Mayer JE, Cook NR, Wernovsky G, et al. Surgical repair of complete atrioventricular canal defects in infancy. Twenty-year trends. J Thorac Cardiovasc Surg. 1993 Sep;106(3):387-94.

16. Boening A, Scheewe J, Heine K, Hedderich J, Regensburger $\mathrm{D}$, Kramer $\mathrm{HH}$, et al. Long-term results after surgical correction of atrioventricular septal defects. Eur J Cardiothorac Surg. 2002 Aug;22(2):167-73.

17. Xie O, Brizard CP, d'Udekem Y, Galati JC, Kelly A, Yong MS, et al. Outcomes of repair of complete atrioventricu- lar septal defect in the current era. Eur J Cardiothorac Surg. 2013 Sep 20.

18. Prifti $E$, Bonacchi $M$, Bernabei $M$, Crucean A, Murzi B, Bartolozzi $F$, et al. Repair of complete atrioventricular septal defects in patients weighing less than $5 \mathrm{~kg}$. Ann Thorac Surg. 2004 May;77(5):1717-26.

19. Mrowczynski W, Wojtalik M, Zawadzka D, Sharma G, Henschke J, Bartkowski R, et al. Infection risk factors in pediatric cardiac surgery. Asian Cardiovasc Thorac Ann. 2002 Dec;10(4):329-33.

20. McGrath LB, Gonzalez-Lavin L. Actuarial survival, freedom from reoperation, and other events after repair of atrioventricular septal defects. J Thorac Cardiovasc Surg. 1987 Oct;94(4):582-90.

21. Suzuki T, Bove EL, Devaney EJ, Ishizaka T, Goldberg CS, Hirsch JC, et al. Results of definitive repair of complete atrioventricular septal defect in neonates and infants. Ann Thorac Surg. 2008 Aug;86(2):596-602.

22. Wetter J, Sinzobahamvya N, Blaschczok C, Brecher AM, Gravinghoff LM, Schmaltz AA, et al. Closure of the zone of apposition at correction of complete atrioventricular septal defect improves outcome. Eur J Cardiothorac Surg. 2000 Feb;17(2):146-53.

Acceptance for editing: 2015-02-10 Acceptance for publication: 2015-03-30

Correspondence address: 27/33 Szpitalna Str. 60-572 Poznań, Poland phone: +48618491277 